\title{
Video Assisted Thoracic Surgery Outcomes for Primary Spontaneous Pneumothorax, Analysis of 56 Cases, Single University Hospital Experience
}

\author{
Fazlı Yanık (D, Yekta Altemur Karamustafaoğlu (D), Yener Yörük (i) \\ Department of Thoracic Surgery, Trakya University School of Medicine, Edirne, Turkey \\ ORCID IDs of the authors: F.Y. 0000-0002-893I-5329; Y.A.K. 0000-0002-549I-I219; Y.Y. 0000-0003-3066-0395.
}

Cite this article as: Yanık F, Karamustafaoğlu YA, Yörük Y. Video Assisted Thoracic Surgery Outcomes for Primary Spontaneous Pneumothorax, Analysis of 56 Cases, Single University Hospital Experience. Cyprus J Med Sci 2018; 3(3): 127-3I.

\section{BACKGROUND/AIMS}

To evaluate patients with primary spontaneous pneumothorax (PSP) who were treated via the video-assisted thoracic surgery (VATS) procedure by means of clinical features, surgical outcomes, and follow-up results.

\section{MATERIAL and METHODS}

We retrospectively analyzed 56 consecutive patients who underwent VATS procedure for PSP between 2012 and 2018 . There were 47 male and 9 female patients with a mean age of 26.01 7.4 (18-38) years. VATS was performed under general anesthesia with double lumen intubation. Apical wedge resection and mechanical abrasion or apical pleurectomy was performed in $60 \%$ of the patients with uniportal VATS and in $40 \%$ of the patients with two portal VATS by the same surgical team.

\section{RESULTS}

The operation indications were recurrence in 40 (71.5\%) patients, prolonged air leak in 14 (25\%), and bilateral pneumothorax in 2 (3.5\%). Pleurodesis procedures included upper pleural mechanical abrasion in 44 (78.5\%) patients and apical pleurectomy in 12 (22.5\%). Bilateral VATS procedure was performed for two patients who had bilateral pneumothorax. The mean operation time, chest tube removal time, and length of hospital stay were $26.04 \pm 4.61$ (20-45) $\mathrm{min}, 1.4 \pm 0.6$ (I-3) days, and $1.7 \pm 0.8(2-4)$ days, respectively. No significant difference was found between uniportal and biportal VATS or mechanical abrasion and apical pleurectomy groups compared with statistical evaluation with demographic and clinical features and surgical outcomes ( $p>0.05)$. There was no mortality, and complications occurred in 16 (28.5\%) patients. Only $3(5.3 \%)$ recurrence occurred during the mean follow-up period of $48.4 \pm 11.4$ (9-70) months.

\section{CONCLUSION}

Video-assisted thoracic surgery stapled bullectomy for PSP when followed by mechanical pleurodesis is still the gold standard and is a reliable, safe method with a low recurrence rate, complication, length of hospital stay, and quicker recovery time. The formation of new bullae-blebs could be related to continued smoking behavior that can be seen as the main reason for late period recurrences.

Keywords: Pneumothorax, VATS, Recurrence

\section{INTRODUCTION}

Primary spontaneous pneumothorax (PSP) is the abnormal accumulation of air into the space between the parietal and the visceral pleura without underlying lung disease; the most commonly suspected reasons are pneumonia and blebs-bullas in the apical lung parenchyma (I, 2). PSP commonly occurs in young, tall, and thin men having high apical pleural negative pressure. The main symptoms are shortness of breath and sudden chest pain. The incidence of PSP is $9 / 100,000$ per year (3). Men are most often affected aged 22 to 26 years old. It is seen $<1 / 5$ in females. When detected in a female patient, it should be considered as a rare cause, such as lymphangioleiomyomatosis or catamenial pneumothorax (4). In recent years, the thoracotomy approach is gradually abandoned. The video-assisted thoracic surgery (VATS) method, which is no longer questionable in terms of less pain, treatment success, less length of hospital stay, and less time to return to work, is preferred in all patients.

The aim of the present study was to retrospectively evaluate patients with PSP who were treated via VATS at our clinic between January 2012 and January 2018. 


\section{MATERIAL and METHODS}

Fifty-six patients with PSP who were treated and followed up were evaluated retrospectively according to age, gender, smoking, etiology, diagnostic methods, treatment modalities, and recurrence. Patients who had secondary spontaneous pneumothorax and traumatic and iatrogenic pneumothorax; $<18$ years old; treated conservatively or with awake non-intubated procedures; and with missing data were excluded from our study. VATS was performed under general anesthesia with double lumen intubation. At the beginning and end of the operation, $0.9 \%$ isotonic solution was fulfilled to the thorax, and the lung was inflated and carefully inspected for possible air leaks, blebs, and bullae. All patients underwent apical wedge resection and mechanical abrasion or apical pleurectomy with uniportal VATS or two portal VATS (if pleural adhesion was detected) by the same surgical team (Figure I). Endoscopic staplers with green cartridges (Endo GIA 604.8 mm, Covidien Endo GIA Universal Roticulator, Minneapolis, MN, USA) were used for wedge resection, and the upper parietal pleura was mechanically abraded by medical sandpaper or apical pleurectomy (Figure 2). During VATS, pleural adhesions were dissected using electrocautery or blunt dissection, if necessary. All patients were extubated in the operating theater and were followed up in the special care section of our service during the first $16 \mathrm{~h}$. Chest physiotherapy was applied in the early postoperative period. Portable chest $X$-ray was performed after surgery within hours. Chest tube of the cases with no air leak and fully expanded on chest $X$-ray was removed. Patients were discharged on the same day or the next day if their expanded lung in PA roentgenogram after the chest tube was removed. All patients were routinely followed up, and the mean follow-up period was 48.4+Il.4 (range 9-70)
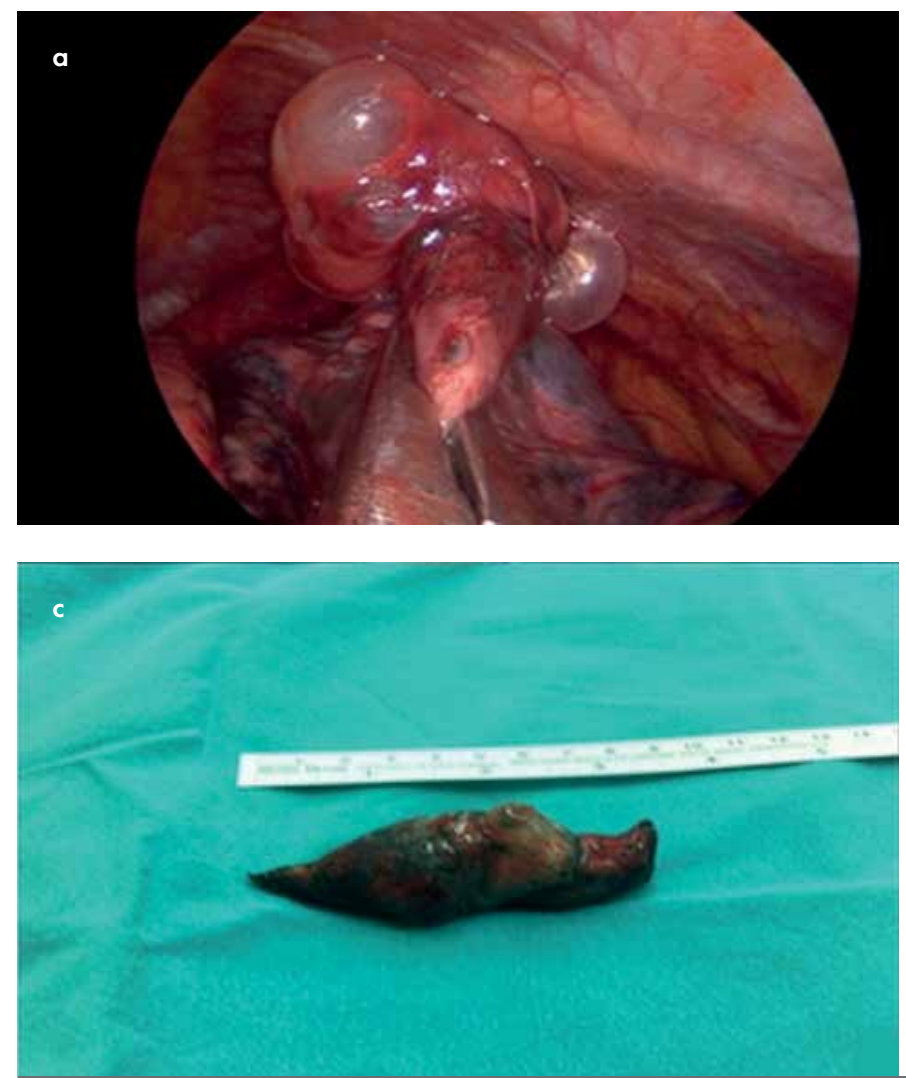

months. Recurrent pneumothorax was defined as a pneumothorax diagnosed by chest $X$-ray or chest tomography $>10$ days after the removal of the chest tube. This research was conducted according to the principles of the World Medical Association Declaration of Helsinki "Ethical Principles for Medical Research Involving Human Subjects" (amended in October 2013).Written informed consent was obtained from patients who participated in this study.

\section{Statistical Analysis}

Statistical analysis was performed using the Statistical Package for the Social Sciences program Statistical Package for the Social Sciences (SPSS) version 20.0 (IBM Corp.; Armonk, NY, USA). Data were expressed as mean $\pm S D$. Frequencies and percentages were used for categorical variables.

\section{RESULTS}

From January 2012 through January 2018, the VATS procedure for PSP was performed in 56 consecutive patients who had a mean age of $26.01 \pm 7.4$ (18-38) years. There were a total of $9(16 \%)$ female and 47 (84\%) male patients. Of the patients, $39(70 \%)$ were treated on the right side, and 17 (30\%) were treated on the left side. Among them, 48 (86\%) had a history of smoking.

The operation indications were recurrence in 40 (71.5\%) patients, prolonged air leak in 14 (25\%), and bilateral pneumothorax in 2 (3.5\%). The operation procedures included upper pleural mechanical abrasion in $44(78.5 \%)$ patients, apical pleurectomy in $12(22.5 \%)$, and uniportal VATS in $34(60 \%)$ and an additional camera port in 22 (40\%). The bilateral VATS procedure was performed in two patients who had bilateral pneumothorax.
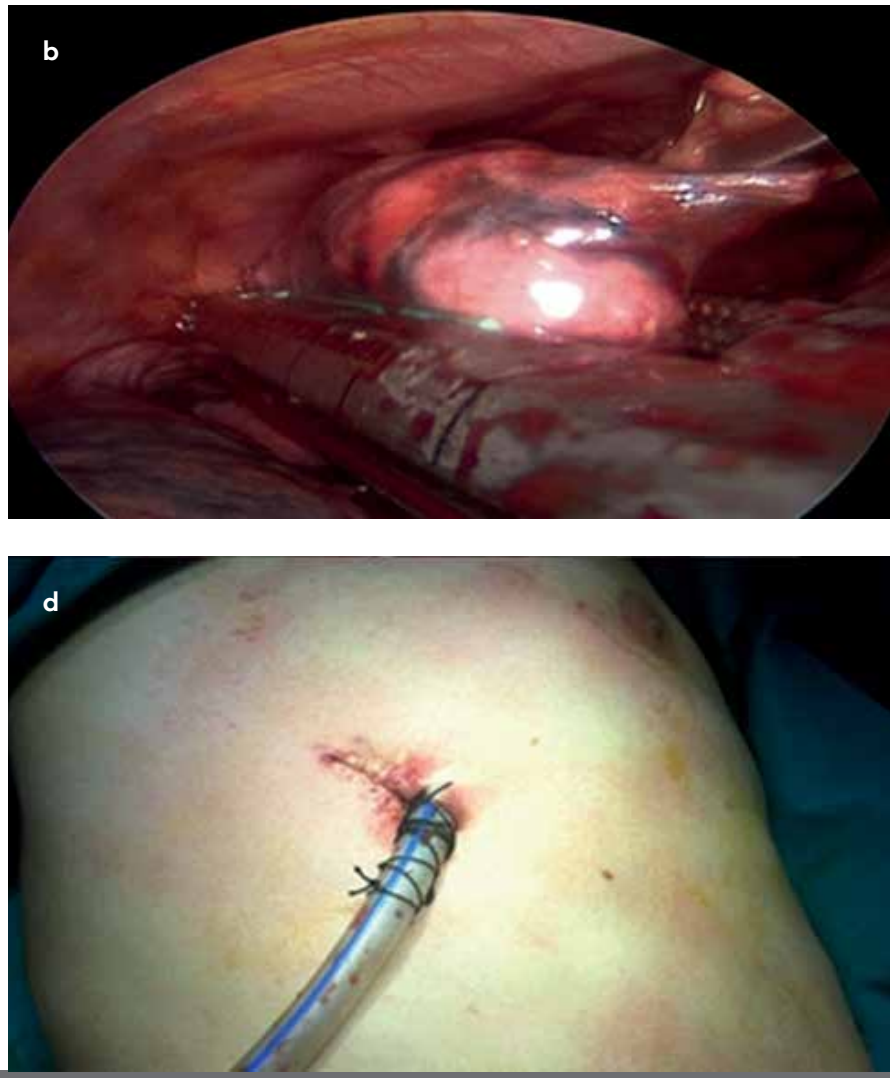

FIGURE I. a-d. VATS image of bullae in the apical segment of the lung (a). VATS image of performing wedge resection with Endo GIA (b). Macroscopic view of blebs after apical segment wedge resection (c). Incision view of the case performed with uniportal VATS procedure (d) 
The mean operation time, chest tube removal time, and length of hospital stay were $26.04 \pm 4.61(20-45) \mathrm{min}, 1.4 \pm 0.6$ (I-3) days, and $1.7 \pm 0.8$ (2-4) days, respectively. Table I shows the other demographic and clinical data and surgical outcomes. No significant difference was found between uniportal and biportal VATS or mechanical abrasion and apical pleurectomy groups compared with statistical evaluation with demographic and clinical features and surgical outcomes ( $p>0.05)$. The mean loss of blood was $<100 \mathrm{~mL}$. We found macroscopic blebs or bullae in 50 (89\%) patients. The mean of staples used was $2.4 \pm 0.6$ (I-5). The mean cost of patient's health care system was calculated as US\$472.42 \pm 56.7 .

There were no conversion of VATS to open thoracotomy and intraoperative complications. Subpleural blebs or bullae (emphysema-like changes) were detected as the definitive pathology of all patients.

In $16(28.5 \%)$ patients who developed complication, it was expansion problems in $8(14.5 \%)$, wound infection in 4 (7.5), recurrence in 3 (5.5\%), and atelectasis requiring bronchoscopy in I $(1,5)$.

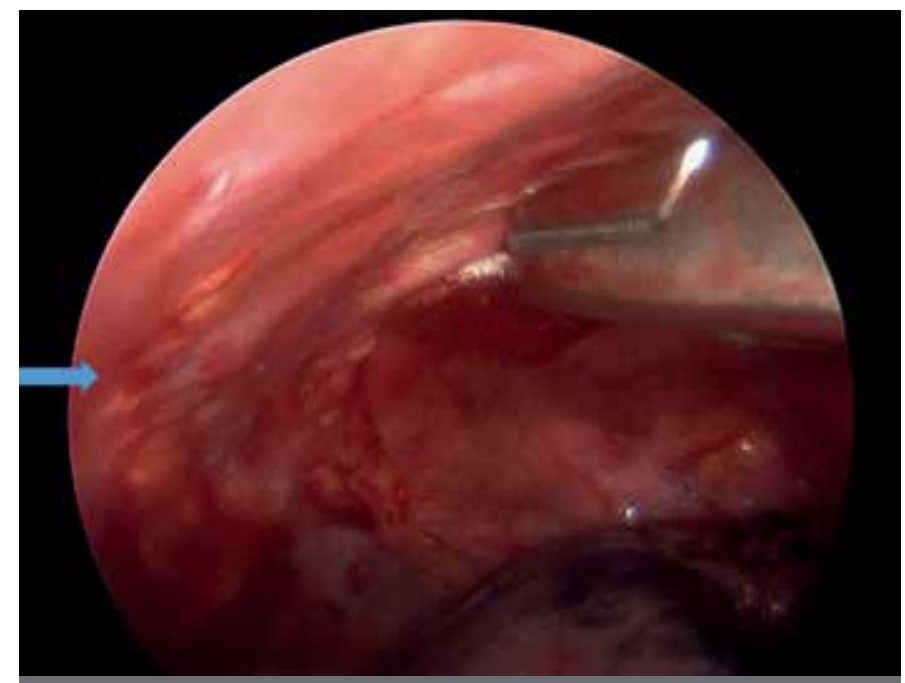

FIGURE 2. Intraoperative VATS view of performing mechanical abrasion of apical pleura with counter sandpaper. Pleural petechiae can be seen, marked with a blue arrow

The months when the first pneumothorax was detected

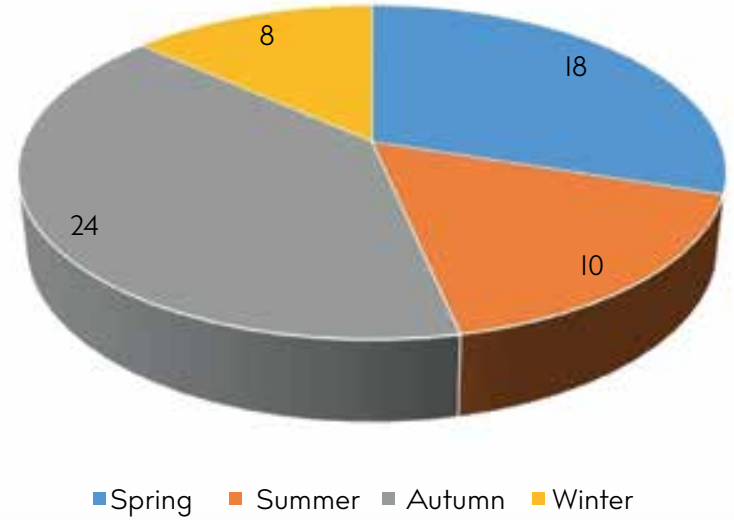

FIGURE 3. Distribution of detected pneumothorax by season
We used an external suction therapy between 20 and $40 \mathrm{~cm}$ $\mathrm{H}_{2} \mathrm{O}$ in eight patients postoperatively. Air leakage stopped on an average of 3 days. For patients who developed wound infection during admission, intravenous antibiotic was administered. No chronic paresthesia was observed in any patient after $>2$ months postoperatively.

When patients are classified according to the first pneumothorax attack, $75 \%$ of them were in the spring and autumn seasons (Figure 3). The peak time of admission to the hospital was recorded in September ( $n=10 ; 17.8 \%)$, with the lean time in February $(n=2 ; 3.5 \%)$.

The mean follow-up period was $48.4 \pm 11.4$ (range 9-70) months. Recurrence was seen in 3 (5.3\%) patients who continued smoking postoperatively. In two patients, recurrence occurred 2 and 3 years postoperatively, respectively. We performed reoperation with VATS, and the newly formed bullous areas were resected, and pleurectomy was added. Tube thoracostomy was applied after 6 months from the first operation for those who did not have an operation. Only pleural abrasion had been performed in three patients who developed recurrence. Recurrence-free times for I year, 2 years, and 6 years were 98.3\%, 96.5\%, and $94.7 \%$, respectively. Intraoperative or postoperative mortality was not observed.

TABLE I. Demographic and clinical characteristics and surgical outcomes of 56 cases

$\begin{array}{lc}\text { Sex, } n(\%) & 56(100) \\ \text {-Male } & 47(84) \\ \text {-Female } & 9(16) \\ \text { Age, mean } \pm \text { SD (range, years) } & 26.01 \pm 7.4(18-38) \\ \text { Mean operation time, mean } \pm S D \text { (range, min) } & 26.04 \pm 4.61(20-45) \text { min } \\ \text { Mean tube removal time, mean } \pm S D \text { (range, min) } & 1.4 \pm 0.6(1-3) \text { days } \\ \text { Mean length of hospital time, mean } \pm S D & 1.7 \pm 0.8(2-4) \text { days } \\ \text { (range, min) } & \\ \text { Access of VATS, } n(\%) & 56(100) \\ \text {-Right } & 39(70) \\ \text {-Left } & 17(30) \\ \text { Smoking history, } n(\%) & 56(100) \\ \text {-Yes } & 48(86) \\ \text {-No } & 8(14) \\ \text { Operation indications, } n(\%) & 56(100) \\ \text { Recurrence } & 40(71.5) \\ \text { Prolonged air leak } & 14(25) \\ \text { Bilateral pneumothorax } & 2(3.5) \\ \text { Complications, } n(\%) & 16(28.5) \\ \text {-Expansion problems } & 8(14.5) \\ \text {-Wound infection } & 4(7.5) \\ \text {-Recurrence } & 3(5.5) \\ \text {-Atelectasis requiring bronchoscopy } & 1(1.5) \\ \text { SD: standard deviatio; VATS: video-assisted thoracic surgery } \\ \end{array}$




\section{DISCUSSION}

Pneumothorax, a disease known since ancient times, has been identified with various clinical approaches and treatment modalities. In addition, PSP is one of the most common problems that a thoracic surgeon encounters in daily practice. The rate of recurrence is $20 \%$ after the first, $60 \%$ second, and $80 \%$ third episodes (5). Cardillo et al. (6) reported that the development rate of PSP in healthy smokers is $12 \%$, whereas it is $0.1 \%$ in non-smokers. They reported that recurrence usually develops in the first 2 years, and the recurrence rate is $1.73 \%$ after VATS procedure. In our study, $84 \%$ of our patients were male, and $86 \%$ had a smoking history. The recurrence rate after VATS procedure was 5.3\% $(3 / 56)$, and two of the recurrences were detected after 2 years.

The British Society of Thoracic Surgeons guidelines on the management of PSP recommended surgery after the first recurrence (7). Other operation indications are persistent air leakage ( $>5-$ 7 days), recurrent ipsilateral pneumothorax, prior contralateral pneumothorax, synchronous bilateral pneumothorax, and occupational risk (aircraft personnel, sportsmen, and scuba divers, etc.). The main goal in surgical management is resection of bullae and blebs and apical pleurodesis to prevent recurrence. Conventional open surgical methods can be used for this, and video-assisted operations are also preferred today. In recent years, VATS is considered as the gold standard surgical technique for the treatment of $\operatorname{PSP}(8,9)$.

Minimally invasive techniques have gradually increased in the last 10 years and also in our own clinic. VATS was considered as the gold standard approach in recurrent PSP. Therefore, in the present study, we wanted to compare our own clinical outcomes with the literature. When VATS is compared with open thoracotomy, the recurrence rates are equal. The superiority of VATS has been proven in many studies in terms of less surgery time, less postoperative pain, shorter hospital stay, less impact of immunity, and shorter time to get started. Therefore, nowadays, it can be said that VATS is associated with better clinical outcomes than thoracotomy for three common thoracic procedures: surgery for pneumothorax, minor resections (wedge and segmental resections), and lobectomy (I0).

The recurrence rate after pneumothorax operations with VATS is $<5 \%$. This rate is approximately $1 \%$ of thoracotomy. Early recurrence (before I month) may be due to inadequate pleurodesis or parenchymal leakage. In case of a late recurrent period (after I month), newly formed blebs and bullae associated with continuing smoking may be responsible. There are also publications that recommend reoperation with VATS and apical pleurectomy in addition to open thoracotomy in recurrences $(2,11-\mid 4)$. In our study, we detected recurrence in $3(5.3 \%)$ patients who continued smoking after VATS procedure. All of them were during the late period, and pleural abrasion had been performed following apical wedge resection. Two patients were reoperated, and apical wedge resection was applied, and pleurectomy was added with VATS. In one patient, tube thoracostomy was performed for denying reoperation.

The recurrence of pneumothorax after VATS surgery is reported to be higher (2\%-14\%) than that after open thoracotomy $(0 \%-7 \%)$. However, this difference is constantly getting smaller with today's VATS techniques (I5). Orki et al. (16) reported their retrospective study of videothoracoscopy bulla ablation using electrocoagulation, and that apical pleurectomy is a safe method for recurrence of PSP with a similar recurrence rate of $4.76 \%$. They concluded that electrocoagulation is cost effective with VATS procedure to avoid the use of expensive stapler devices.

There are many studies comparing the uniportal or multiportal performance of VATS technique for PSP. When the uniportal VATS was compared with the traditional three port VATS for PSP, better cosmetic results, shorter hospital stay, less postoperative pain, short recovery time, and more cost effective were found $(17,18)$. In our study, $60 \%$ of the patients underwent uniportal VATS, and reasonable results were obtained regarding length of hospital stay, restore time, and economic parameters consistent throughout the literature. None of our 56 patients had chronic paresthesia after the procedure.

Akyil et al. (19) evaluated the correlation between meteorological conditions and pneumothorax with a total of 1097 patients with PSP in their study. They reported that the peak time of admission to the hospital is recorded in $\operatorname{October}(n=|3| ; 12 \%)$ and in autumn ( $n=330 ; 30 \%)$. In our study, we found that $75 \%$ of the patients' first pneumothorax attack were in the spring and autumn seasons (September: $n=10 ; 17.8 \%$ ).

Our study has some limitations. First, it is a retrospective study including consecutive patients and is open to selection bias. Second, we use no direct comparison with conservative treatment or other VATS techniques. However, the strength of our study is that we performed a standard VATS procedure in all patients and evaluated from many perspectives related to PSP.

Primary spontaneous pneumothorax, which has been known since ancient times, is still one of the most frequent diseases that thoracic surgeons encounter. In terms of low major complications, low recurrence, short hospital stay, low postoperative paresthesia, and short recovery time, VATS without regard to uniportal or multiportal is still the gold standard and is a safe method for PSP. Mechanical abrasion or apical pleurectomy can be performed with similar success rates. The formation of new bullae-blebs associated with continued smoking behavior can be seen as the main reason for late period recurrences.

Ethics Committee Approval: The authors declared that the research was conducted according to the principles of the World Medical Association Declaration of Helsinki "Ethical Principles for Medical Research Involving Human Subjects" (amended in October 2013).

Informed Consent: Written informed consent was obtained from patients who participated in this study.

Peer-review: Externally peer-reviewed.

Author contributions: Concept - F.Y., Y.A.K.; Design - F.Y., Y.Y.; Supervision - Y.A.K., Y.Y.; Resource - F.Y., Y.A.K.; Materials - F.Y.,.A.K.; Data Collection and/or Processing - F.Y., Y.Y.; Analysis and/or Interpretation - F.Y., Y.A.K., Y.Y.; Literature Search - F.Y., Y.A.K., Y.Y.; Writing - F.Y, Y.A.K.; Critical Reviews - Y.A.K., Y.Y.

Conflict of Interest: The authors have no conflicts of interest to declare.

Financial Disclosure: The authors declared that this study has received no financial support. 


\section{REFERENCES}

I. Cho S, Jheon S, Kim DK, Kim HR, Huh DM, Lee S, et al. Results of repeated video-assisted thoracic surgery for recurrent pneumothorax after primary spontaneous pneumothorax. Eur J Cardiothorac Surg 2017; 53: 857-61. [CrossRef]

2. Sadikot RT, Greene T, Meadows K, Arnold AG .Recurrence of spontoneus pneumothorax. Thorax 1997; 52: 805-9. [CrossRef]

3. Bertolaccini L, Pardolesi A, Brandolini J, Solli P. Uniportal video-assisted thoracic surgery for pneumothorax and blebs/bullae $\mathrm{J} V$ is Surg 2017; 3: 107. [CrossRef]

4. Visouli AN, Darwiche K, Mpakas A, Zarogoulidis P, Papagiannis A, Tsakiridis K et al. Catamenial pneumothorax: a rare entity? Report of 5 cases and review of the literature. J Thorac Dis 2012; 4 (Suppl I): 17-31.

5. Chan P, Clarke P, Daniel FJ, Knight SR and Seevanayagam S. Efficacy Study of Video-Assisted Thoracoscopic Surgery Pleurodesis for Spontaneous Pneumothorax. Ann Thorac Surg 200I; 7l: 452-4. [CrossRef]

6. Cardillo G, Carleo F, Giunti R, Carbone L, Mariotta S, Salvadori L, et al. Videothoracoscopic talc poudrage in primary spontaneous pneumothorax: A single-institution experience in 861 cases. J Thorac Cardiovasc Surg 2006; 131: 322-8. [CrossRef]

7. MacDuff A, Arnold A, Harvey J. Management of spontaneous pneumothorax: British Thoracic Society Pleural Disease Guideline 2010. Thorax 20I0; 65 (Suppl 2): 18-31. [CrossRef]

8. Ramzi AA, Farid MS, Sudhir RS, Patrick JV, Andrew JE, Sebastien G, et al. Is VATS Bullectomy and Pleurectomy an Effective Method for the Management of Spontaneous Pneumothorax? Open Journal of Thoracic Surgery 2016; 6: 25-31. [CrossRef]

9. Baumann MH, Strange $C$, Heffner JE, Light R, Kirby TJ, Klein J, et al. ACCP Delphi Consensus Statement Management of spontaneous pneumothorax. Chest 2001; 119: 590-602. [CrossRef]

10. Sedrakyan A, Meulen J, Lewsey J, Treasure T. Video assisted thoracic surgery for treatment of pneumothorax and lung resections: systematic review of randomised clinical trials. BMJ 2004; 329: 1008-16. [CrossRef]
II. Dagnegård HH, Rosén A, Sartipy U, Bergman P. Recurrence rate after thoracoscopic surgery for primary spontaneous pneumothorax. Scand Cardiovasc J 2017; 51: 228-32. [CrossRef]

12. Takahashi R. Evaluation of Spontaneous Pneumothorax Surgeries: A 16-Year Experience in Japan. Surgery Research and Practice 2016; I: I-7 [CrossRef]

13. Cardillo G, Facciolo F, Giunti R, Gasparri R, Lopergolo M, Orsetti R et al. Videothoracoscopic treatment of primary spontaneous pneumothorax: A 6-year experience. Ann Thorac Surg 2000; 69: 357-62. [CrossRef]

14. Cardillo G, Faccioloa F, Regala M, Carbone L, Corzani F, Ricci A et al. Recurrences following videothoracoscopic treatment of primary spontaneous pneumothorax: the role of redovideothoracoscopy. Eur J Cardiothorac Surg 200I; 19: 396-9. [CrossRef]

15. $\mathrm{Ng}$ CS, Lee TW, Wan S, Yim AP. Video assisted thoracic surgery in the management of spontaneous pneumothorax: the current status. Postgrad Med J 2006; 82: 179-85. [CrossRef]

16. Orki A, Demirhan R, Ciftci H, Coskun T, Kutlu CA, Arman B. Videothoracoscopic approach to recurrence primary spontaneous pneumothorax: using of electrocoagulation in small bulla/blebs. Indian J Surg 2009; 7I: 19-22. [CrossRef]

17. Jutley RS, Khalil MW, Rocco G. Uniportal vs standard three-port VATS technique for spontaneous pneumothorax: comparison of post-operative pain and residual paraesthesia. Eur J Cardiothorac Surg 2005; 28: 43-6. [CrossRef]

18. Salati M, Brunelli A, Xiume F, Refai $M$, Sciarra $V$, Soccetti $A$, et al. Uniportal videoassisted thoracic surgery for primary spontaneous pneumothorax: Clinical and economic analysis in comparison to the traditional approach. Interact Cardiovasc Thorac Surg 2008; 7: 63-6. [CrossRef]

19. Akyıl M, Tezel C, Evman S, Kanbur S, Vayvada MM, Akyıl FT, et al. Correlation between meteorological conditions and pneumothorax: Myth or fact? Interactive CardioVascular and Thoracic Surgery, 2015; 2I (Suppl I): S36-S4I. [CrossRef] 